\title{
Ni nanoparticle modified graphite electrode for methanol electrocatalytic oxidation in alkaline media
}

\author{
Gh. S. Ferdowsi · S. A. Seyedsadjadi • \\ A. Ghaffarinejad
}

Received: 5 June 2014/Accepted: 3 September 2014/Published online: 11 September 2014

(C) The Author(s) 2014. This article is published with open access at Springerlink.com

\begin{abstract}
Ni nanoparticles with an electroless procedure were deposited on the graphite rod, and the performance of the proposed electrode was evaluated for electrocatalytic oxidation of methanol in alkaline media. The structure and morphology of the electrode surface were examined with $\mathrm{X}$-ray diffraction, energy dispersive $\mathrm{X}$-ray analysis and scanning electron microscopy techniques. Voltammetric and amperometric studies indicated that the onset potential of the methanol oxidation is low $(0.42 \mathrm{~V})$ and the electrode stability is good. In addition to these advantages, due to ease of preparation and low cost, it can be used as an anode in methanol fuel cells.
\end{abstract}

Keywords Electroless deposition - Methanol electrocatalytic oxidation - Graphite electrode $\cdot$ Nickel nanoparticles

Gh. S. Ferdowsi $\cdot$ S. A. Seyedsadjadi

Faculty of Chemistry, Iran University of Science and

Technology, Tehran 1684613114, Iran

e-mail: ferdowsi@chem.iust.ac.ir

S. A. Seyedsadjadi

e-mail: seyedsadjadi@iust.ac.ir

A. Ghaffarinejad $(\bowtie)$

Research Laboratory of Real Samples Analysis, Faculty of Chemistry, Iran University of Science and Technology,

Tehran 1684613114, Iran

e-mail: Ghaffarinejad@iust.ac.ir

A. Ghaffarinejad

Electroanalytical Chemistry Research Centre, Iran University of

Science and Technology, Tehran 1684613114, Iran

\section{Introduction}

In the last 40 years, a lot of interest has been focused on the viability of direct methanol fuel cells (DMFCs) as an effective power source in transportation and portable electronic devices [1]. The use of methanol as a fuel has several advantages such as: the energy density of methanol is twice that gained from the liquid hydrogen, rapid start up and operation, methanol is a liquid at normal ambient temperatures, thus it can be easily and inexpensively stored and transported. It is handled much like gasoline and diesel fuel. Moreover, methanol is independent on crude oil, a vital factor with the demand for constant increased mobility and is easily obtained from natural gas or renewable biomass resources.

Since the kinetics of methanol oxidation reaction are slow and incomplete, a catalyst is required to improve the oxidation efficiency [2]. A large number of electrocatalysts have been used for oxidation of methanol, which among them the electrocatalysts based on Pt [3, 4] and Pt alloys [5, 6] have a good activity for methanol oxidation, but adsorption of carbon monoxide on Pt tends to slow down the kinetics of oxidation reaction [7], and in addition, the high cost of Pt metal is another limitation. Therefore, many attempts have been done toward the examination of the catalytic activity of cheap metals such as nickel-based materials [8-10]. Nickel and nickel oxy-hydroxide are good materials for the oxidation of organic compounds in alkaline solutions [11].

There are a few reports which have used Ni nanoparticles on composite graphite [12] and specially on graphene sheets [13] or Ni hydroxide nanoparticles [14, 15] as electrocatalyst for methanol oxidation reaction (MOR).

In this research paper, we used the electroless method for deposition of nickel nanoparticles on the graphite rod as 
a modified electrode. Then the performance of the proposed electrode was examined for electrocatalytic oxidation of methanol, and a mechanism was proposed for the electrochemical reaction. The preparation method is very cheap, and the performance and stability of the electrode response are good.

\section{Experimental}

Materials and solutions

Methanol, Nickel (II) sulfate hexahydrate, ammonium sulfate, sodium hydroxide, tin (II) chloride and sodium dodecyl sulfate all were of analytical grade and were purchased from Merck. Palladium (II) chloride (59\%), formaldehyde-sodium and sodium hypophosphite were purchased from Merck. All solutions were prepared with deionization water.

\section{Apparatus}

The electrochemical measurements were done with a potentiostat-galvanostat (SAMA 500, Iran). The three-electrode system consisted of the bare or modified graphite rod (graphite electrode in Sony ${ }^{\circledR}$ commercial dry cell batteries, $r=2 \mathrm{~mm})$ as working electrode, $\mathrm{Ag} / \mathrm{AgCl}(3 \mathrm{M} \mathrm{KCl})$ as a reference electrode and a $\mathrm{Pt}$ wire as a counter electrode. For obtaining a reproducible surface, the rod was surrounded tightly with a Teflon tube and was polished with fine emery papers to obtain a mirror-like surface.

The surface morphology was observed with a Philips scanning electron microscope model of VEGA TESCAN. The model of energy dispersive analysis instrument was TESCAN VEGA-XMU.

XRD studies were performed at room temperature $\left(25^{\circ} \mathrm{C}\right)$ by Philips X-ray diffractometer model PW1800.

Preparation of electrodes modified with nickel nanoparticles

Nickel nanoparticles (Ni-NP) were deposited on the graphite surface with an electroless procedure. Before deposition, the graphite electrode was polished with emery papers in different grades until a mirror-like surface was obtained. For removing any organic pollutants, the electrode surface was cleaned with acetone in ultrasonic bath for about $10 \mathrm{~min}$, and then the electrode was washed with deionized water.

The preparation of Ni-NP coated graphite involved an initial pretreatment of graphite and a subsequent reduction process. A two-step pretreatment [16], sensitization and activation, was used for catalyzing the graphite. The sensitizer and activator were stannous chloride/hydrochloric acid and palladium chloride/hydrochloric acid solution, respectively. First the electrode was dipped in $40 \mathrm{~mL}$ aqueous solution containing $0.4 \mathrm{~g} \mathrm{SnCl}_{2}+1.6 \mathrm{~mL}$ concentrated $\mathrm{HCl}$, then washed with deionized water, and after this dipped in $40 \mathrm{~mL}$ solution containing $0.01 \mathrm{~g} \mathrm{PdCl}_{2}+5$ drops $\mathrm{HCl}+\mathrm{H}_{2} \mathrm{O}$. The time and temperature for both steps were $30 \mathrm{~min}$ and $367 \mathrm{~K}$, respectively. After activation, graphite electrode was washed and introduced in the electroless nickel-plating bath at $358 \mathrm{~K}$ with the stirring speed of $200 \mathrm{rpm}$. The bath composition contained Nickel(II) sulfate $\left(42 \mathrm{~g} \mathrm{~L}^{-1}\right), \quad$ formaldehyde-sodium $\left(15 \mathrm{~mL} \mathrm{~L}^{-1}\right)$, sodium dodecyl sulfate $\left(2 \mathrm{~g} \mathrm{~L}^{-1}\right)$ and ammonium sulfate $\left(66 \mathrm{~g} \mathrm{~L}^{-1}\right)$, which the role of each component was source of $\mathrm{Ni}$ (II), reducing agent, stabilizer and buffering agent, respectively.

\section{Results and discussion}

$\mathrm{XRD}$ and SEM analysis

The surface morphology of the Ni-NP modified graphite electrode (NiNP-GE) was observed with SEM. The images of this study in two magnifications are shown in Fig. 1 (a, b). The figure shows that the Ni particles are produced successfully in nanosize scale. As Fig. 1 shows, the Ni particle sizes are smaller than $100 \mathrm{~nm}$.

Also the EDX analysis was carried out, which the result is shown in Fig. 1(c). As this figure illustrates only pure $\mathrm{Ni}$ particles were deposited on the graphite rod.

In another experiment, the surface composition was investigated with XRD technique (Fig. 2). In this figure the peaks related to $\mathrm{Ni}$ and carbon are marked. The pattern shows that the Ni-NPs are pure and there is not any impurity in the coating.

As Fig. 1 shows, the most of Ni particle sizes are smaller than $100 \mathrm{~nm}$, therefore the Scherrer equation (Eq. 1) can be used for estimating the nanoparticle size [17].

$\tau=\frac{K \lambda}{\beta \cos \theta} \quad$ (Scherrerequation)

In this equation, $\tau$ is the mean size of the ordered (crystalline) domains, which may be smaller or equal to the grain size; $K$ is a dimensionless so-called shape factor, which usually takes a value of about $0.9 ; \lambda$ is the $\mathrm{X}$-ray wavelength; $\beta$ is the line broadening at half the maximum intensity (FWHM), after subtracting the instrumental line broadening, its unit must be in radians, and $\theta$ is the Bragg angle in degree. According to Eq. 1, the mean size of the $\mathrm{Ni}$ nanoparticles was $23.3 \mathrm{~nm}$ which was in good agreement with the SEM images. 
Fig. 1 SEM images of electroless coating of nickel nanoparticles on graphite electrode with two magnifications $(\mathbf{a}, \mathbf{b})$, and energy dispersive spectrum of a $\mathrm{Ni}$-NP coated graphite electrode (c)
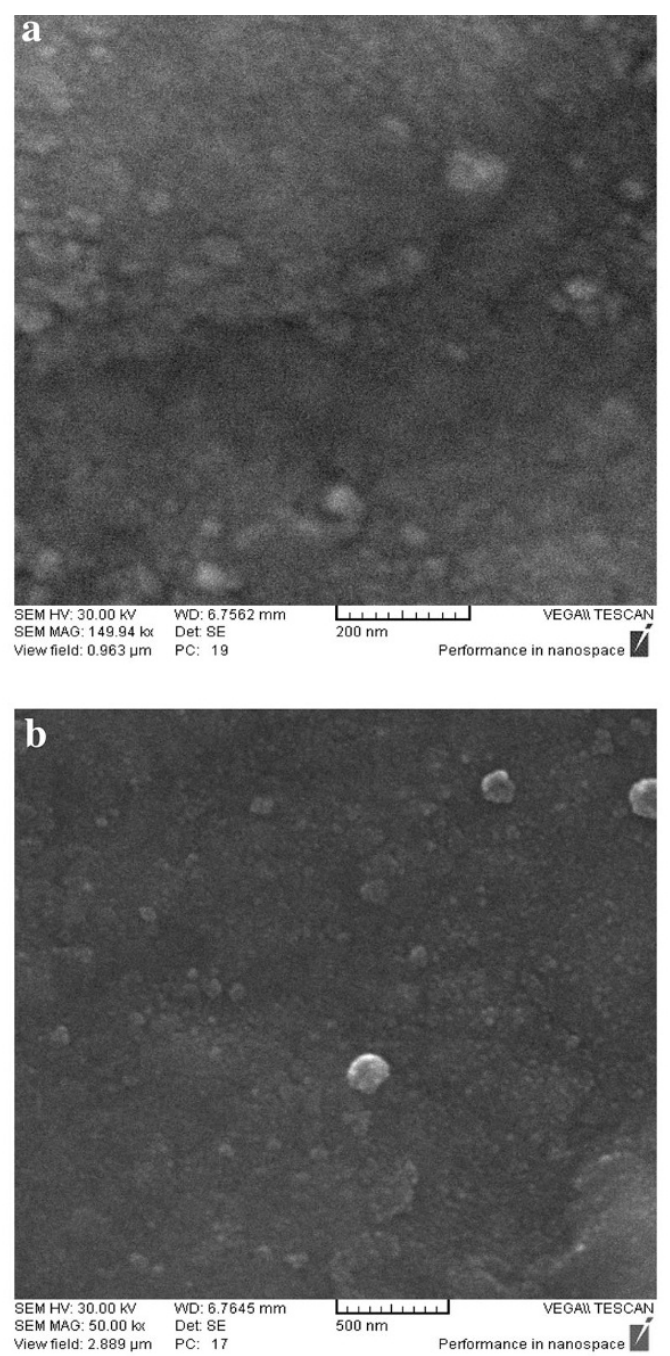

C 3000

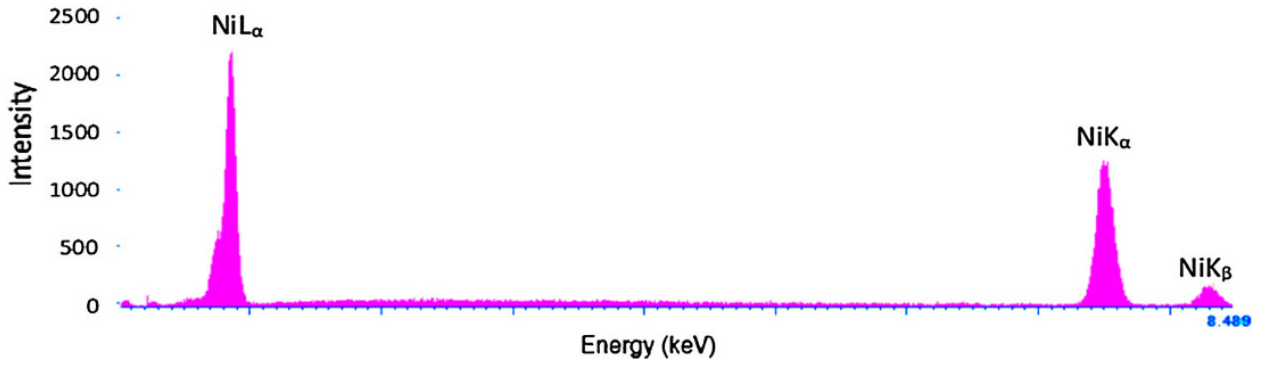

\section{Electrochemical studies}

Figure 3 shows the cyclic voltammogram of NiNP-GE in $0.1 \mathrm{M} \mathrm{NaOH}$ solution in the potential range from 0 to $0.8 \mathrm{~V}$ with the scan rate of $100 \mathrm{mV} \mathrm{s}^{-1}$. A redox couple peaks appears at potential values of 0.498 and $0.256 \mathrm{~V}$ which are attributed to $\mathrm{Ni}(\mathrm{OH})_{2} / \mathrm{NiOOH}$ transformation [11].
Figure 4 represents the cyclic voltammograms of NiNP$\mathrm{GE}$ in $0.1 \mathrm{M} \mathrm{NaOH}$ solution at various scan rates $\left(v=20-100 \mathrm{mV} \mathrm{s}^{-1}\right)$. It is observed that as the scan rate increases, the current density of $\mathrm{Ni}(\mathrm{II}) / \mathrm{Ni}$ (III) redox couple increases. In addition, the anodic peak shows a potential shift toward more positive values, while the cathodic peak is shifted toward more negative potential values. As the inset of Fig. 4 shows, the oxidation peak currents of $\mathrm{Ni}(\mathrm{II}) /$ 
Fig. 2 XRD pattern of electroless coating of nickel nanoparticles on graphite electrode

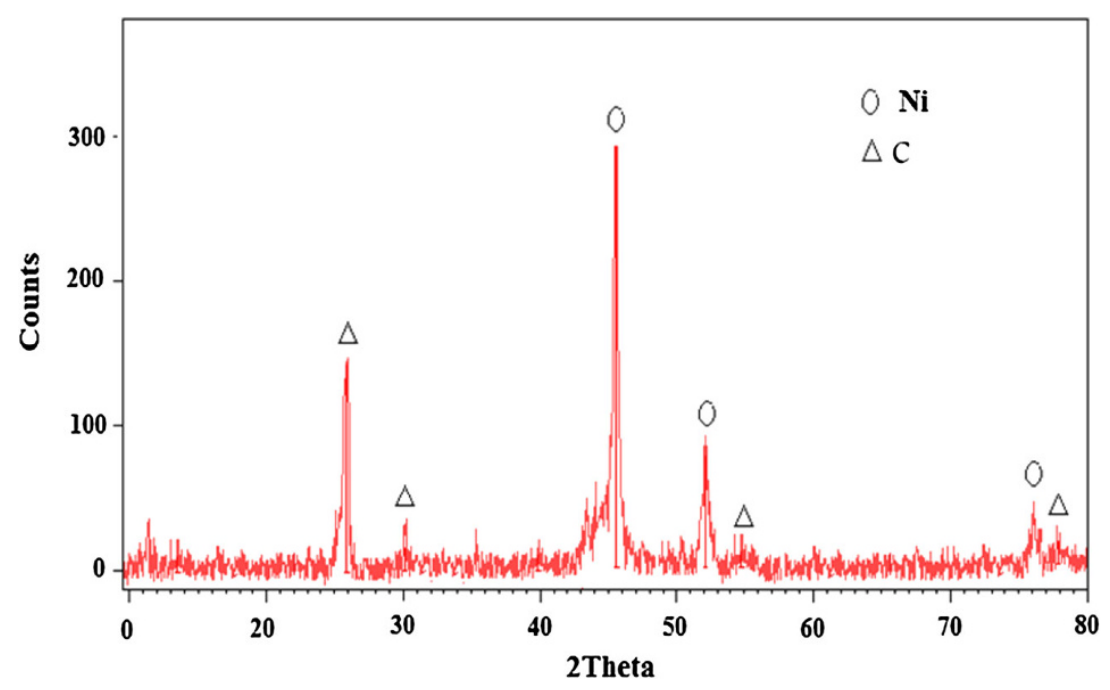

$\mathrm{Ni}$ (III) are linearly proportional to the scan rate, which means this reaction is surface confined.

The surface coverage $(\Gamma)$ of NiNPs was estimated from the equation $\Gamma=Q / \mathrm{nFA}[18]$, which was $1.4 \times 10^{-10}$ mol $\mathrm{cm}^{-2}$. In this equation, $Q$ is the area under the anodic peak after background correction at scan rate of $20 \mathrm{mV} \mathrm{s}^{-1}, n, F$ and $A$ are the number of electrons involved in the redox reaction, Faraday constant and electrode area, respectively.

Figure 5 compares the responses of GE and NiNP-GE in $0.1 \mathrm{M} \mathrm{NaOH}$ solution containing $0.5 \mathrm{M}$ methanol. As the figure shows related to bare $\mathrm{GE}$, in the presence of the $\mathrm{Ni}$ nanoparticles the overvoltage for methanol oxidation decreases and the current density increases considerably.

For the oxidation of methanol using electrode covered by nickel hydroxide in alkaline solution, different hypotheses were given in the literature [19]. Fleischmann et al. [20] proposed a mechanism of alcohols oxidation and suggested that $\mathrm{NiOOH}$ acts as an electrocatalyst. This suggestion was mainly based on the experimental observation that alcohols and other organic compounds were oxidized at a potential value which coincided exactly with that where $\mathrm{NiOOH}$ was produced and on the disappearance of $\mathrm{NiOOH}$ reduction peak in the cathodic sweep [2]. However, the role of $\mathrm{NiOOH}$ as an electrocatalyst for methanol oxidation has been questioned by many authors. Some researchers reported that methanol oxidation takes place after the complete oxidation of $\mathrm{Ni}(\mathrm{OH})_{2}$ to $\mathrm{NiOOH}$. El-Shafei [11] studied the oxidation of methanol at nickel hydroxide/glassy carbon modified electrode in alkaline medium and found that methanol oxidation occurred via $\mathrm{Ni}$ (III) species (mainly NiOOH). The other mechanism was introduced

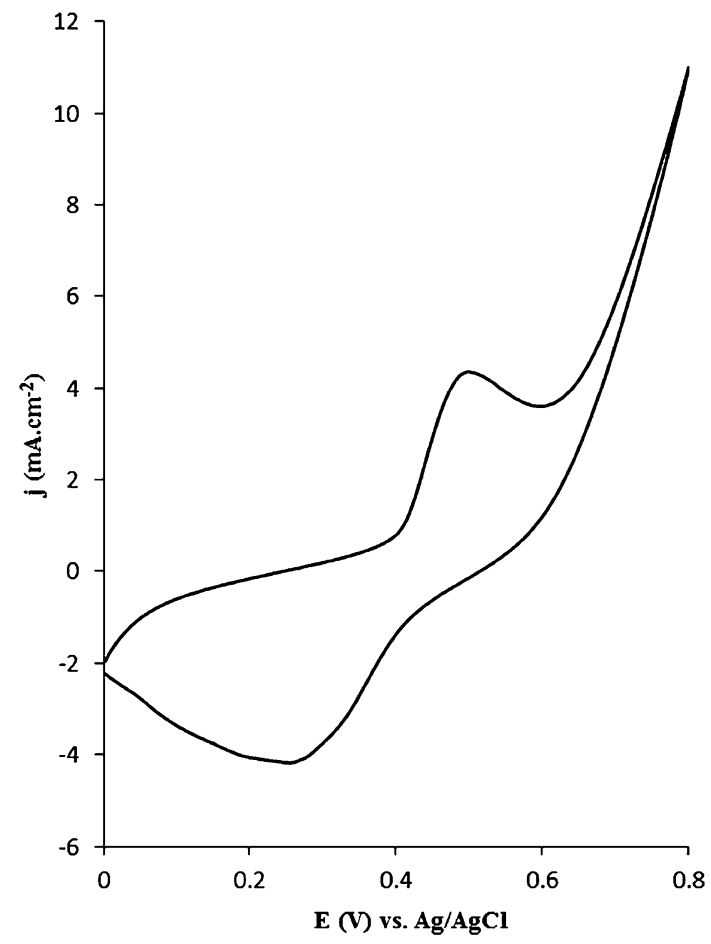

Fig. 3 Cyclic voltammogram of NiNP-GE in $0.1 \mathrm{M} \mathrm{NaOH}$ solution at $100 \mathrm{mV} \mathrm{s}^{-1}$ in the potential range from 0 to $0.8 \mathrm{~V}$

by Taraszewska et al. [21], which supposed methanol molecules penetrate the nickel hydroxide film and are oxidized by $\mathrm{OH}$ ions trapped in the film. According to our results that based on the start of methanol oxidation at the potential of $\mathrm{Ni}(\mathrm{OH})_{2} / \mathrm{NiOOH}$ conversion, we can suggest a mediated electron transfer mechanism involving nickel oxidation states in agreement with that proposed by Fleischmann et al. [20] as follows: 


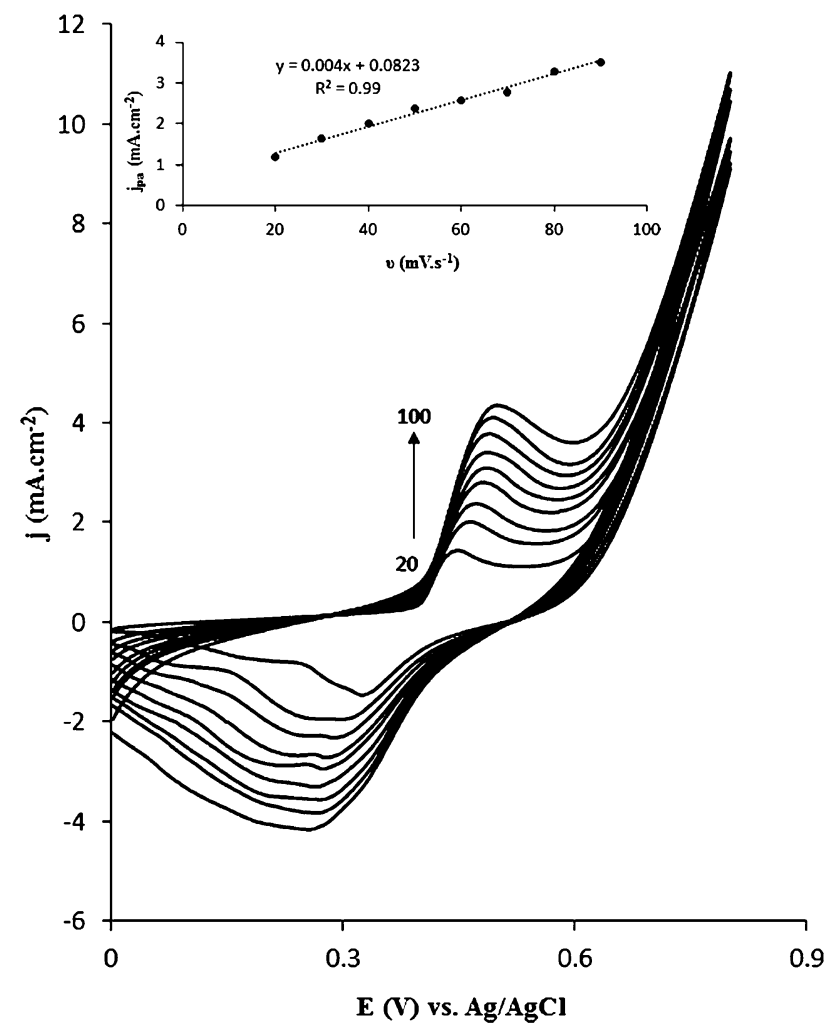

Fig. 4 Cyclic voltammograms of NiNP-GE in $0.1 \mathrm{M} \mathrm{NaOH}$ solution at different scan rates $\left(20,30,40,50,60,70,80,90\right.$ and $\left.100 \mathrm{mV} \mathrm{s}^{-1}\right)$. The linear dependence of the anodic peak currents on the scan rate

$$
\begin{aligned}
\mathrm{Ni}(\mathrm{OH})_{2}+\mathrm{OH}^{-} \rightarrow & \mathrm{NiOOH}+\mathrm{H}_{2} \mathrm{O}+\mathrm{e}^{-} \\
\mathrm{NiOOH}+\text { methanol } \rightarrow & \mathrm{Ni}(\mathrm{OH})_{2} \\
& + \text { oxidation product "slow step", }
\end{aligned}
$$

Chronoamperometry Studies

In this study the chronoamperograms at $0.8 \mathrm{~V}$ were obtained for different concentration of methanol in alkaline solution (Fig. 6). The response of the electrode is increased with the increase of the methanol concentration. Also in another experiment several successive potential steps were applied on the NiNP-GE in $0.5 \mathrm{M}$ methanol. In this experiment the base potential was $0 \mathrm{~V}$ with $10 \mathrm{~s}$ duration and the step potential was $1 \mathrm{~V}$ with $120 \mathrm{~s}$ duration (Fig. 7). The current density after applying each potential step was measured and the RSD for 10 successive applied step potentials was $4.1 \%$ which is acceptable and showed that the response of the electrode is stable and not influenced by the oxidation products.

Fleischmann et al. [20] studied the oxidation of organic compounds on the $\mathrm{Ni}$ anode in alkaline solution. Comparing to this report, the current density of

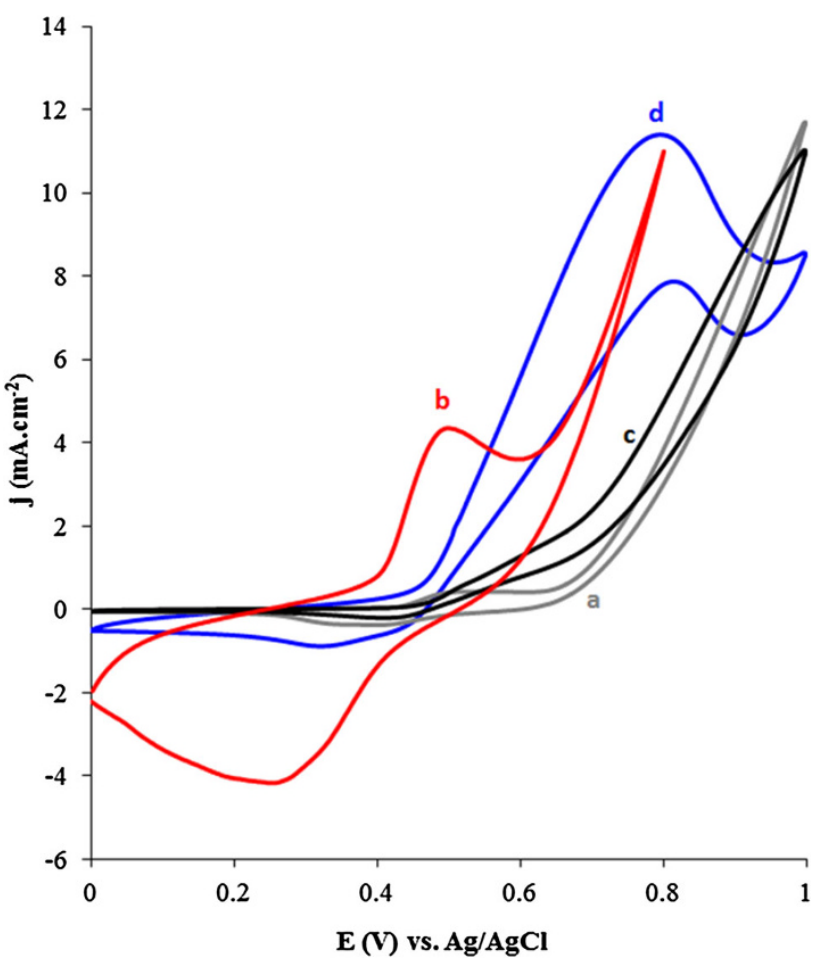

Fig. 5 Cyclic voltammograms of GE (a) and NiNP-GE (b) in $0.1 \mathrm{M}$ $\mathrm{NaOH}$ solution, and GE (c) and NiNP-GE (d) in $0.1 \mathrm{M} \mathrm{NaOH}$ containing $0.5 \mathrm{M}$ methanol. Scan rate: $100 \mathrm{mV} \mathrm{s}^{-1}$

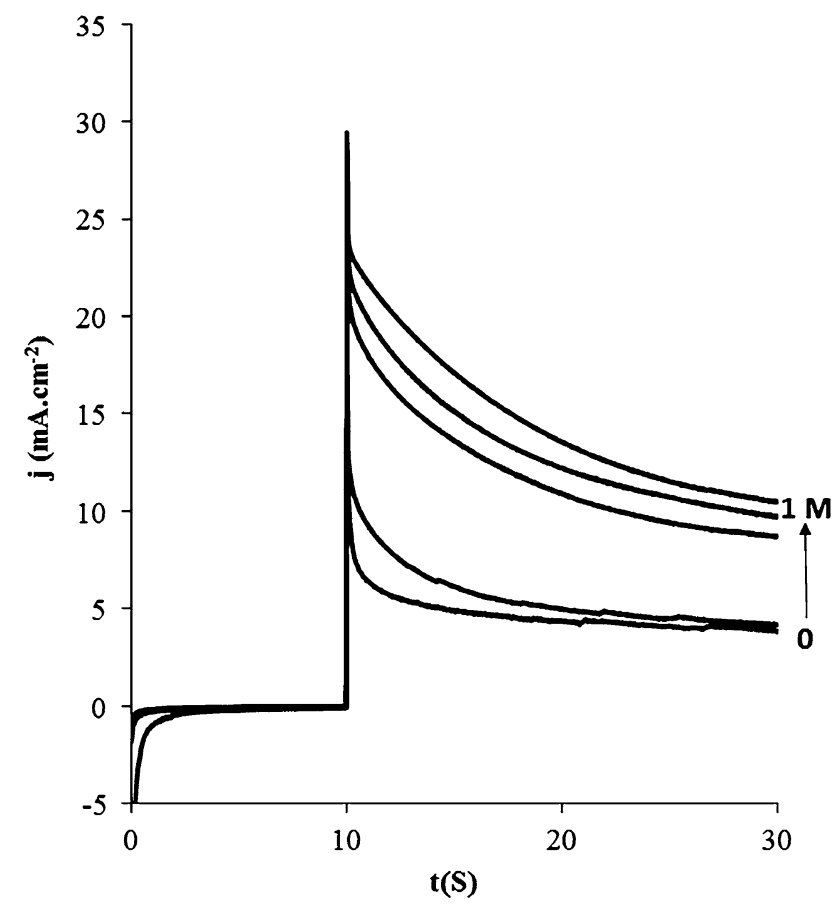

Fig. 6 Chromoamperograms at different concentrations of methanol $(0,0.1,0.5,0.7$ and $1 \mathrm{M})$ in $0.1 \mathrm{M} \mathrm{NaOH}$. Step potential: $0.8 \mathrm{~V}$

methanol oxidation on NiNP-GE is greater. Abdel Rahim et al. [22] have reported electrochemically $\mathrm{Ni}$ dispersed on graphite electrode for electro-oxidation of 
Fig. 7 Several successive potential steps on the NiNP-GE in $0.1 \mathrm{M} \mathrm{NaOH}$ containing $0.5 \mathrm{M}$ methanol

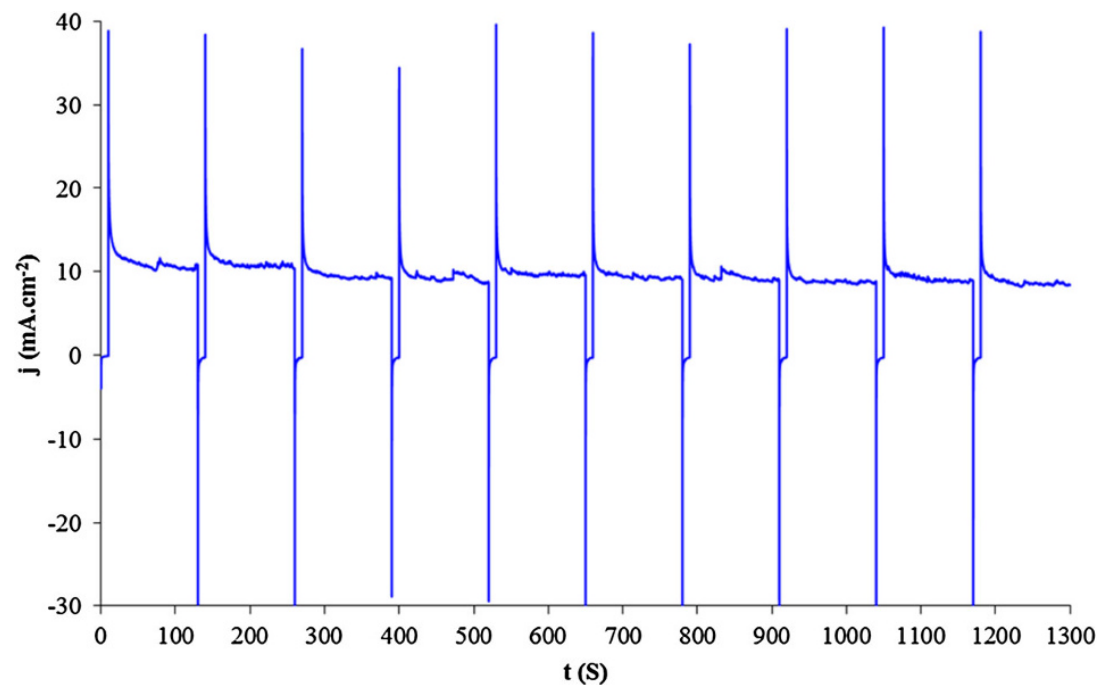

methanol in alkaline medium. In comparison with this report, the peak potential in our proposed electrode is about $450 \mathrm{mV}$ smaller. Also there are some reports which have used modified carbon or GCE with nanocrystalline $\mathrm{Ni}$ [12], GCE with $\mathrm{Ni}$ [23], $\mathrm{Ni}$ films on GCE, GE and Ti [24], Ni hollow spheres [25] for methanol electro-oxidation. Although the proposed electrode in our study could not improve the oxidation potential or the current density, but the deposition potential is simpler and does not require any potentiostat or galvanostat. Also with the electroless procedure the adherence of the Ni particles on the electrode surface is stronger than electrodeposition method.

\section{Conclusion}

In this study, $\mathrm{Ni}$ nanoparticles with an electroless method were deposited on the graphite electrode. Relative to graphite electrode, this modified electrode has lower onset potential with higher anodic current density for methanol oxidation. Due to ease of preparation, and high performance, and good adherence of $\mathrm{Ni}$ nanoparticles, the proposed electrode is a good anode for methanol fuel cells.

Acknowledgments We gratefully acknowledge the support of this work by the research councils of Iran University of Science and Technology.

Open Access This article is distributed under the terms of the Creative Commons Attribution License which permits any use, distribution, and reproduction in any medium, provided the original author(s) and the source are credited.

\section{References}

1. Amin, R.S., Hameed, R.M.A., El-Khatib, K.M., Youssef, M.E., Elzatahry, A.A.: Pt-NiO/C anode electrocatalysts for direct methanol fuel cells. Electrochim. Acta 59, 499-508 (2012)

2. Hameed, R.M.A., El-Khatib, K.M.: Ni-P and Ni-Cu-P modified carbon catalysts for methanol electro-oxidation in $\mathrm{KOH}$ solution. Int. J. Hydrogen Energy 35, 2517-2529 (2010)

3. Liu, J., Ye, J., Xu, C., Jiang, S.P., Tong, Y.: Electro-oxidation of methanol, 1-propanol and 2-propanol on Pt and Pd in alkaline medium. J. Power Sources 177, 67-70 (2008)

4. Huang, H.X., Chen, S.X., Yuan, Ce: Platinum nanoparticles supported on activated carbon fiber as catalyst for methanol oxidation. J. Power Sources 175, 166-174 (2008)

5. Wang, Z., Shi, G., Xia, J., Xia, Y., Zhang, F., Xia, L., Song, D., Liu, J., Li, Y., Xia, L., Brito, M.E.: Facile preparation of a Pt/ Prussian blue/graphene composite and its application as an enhanced catalyst for methanol oxidation. Electrochim. Acta 121, 245-252 (2014)

6. Zhan, F., Bian, T., Zhao, W., Zhang, H., Jin, M., Yang, D.: Facile synthesis of Pd-Pt alloy concave nanocubes with high-index facets as electrocatalysts for methanol oxidation. Cryst. Eng. Comm. 16, 2411-2416 (2014)

7. Scott, K., Taama, W.M., Argyropoulos, P., Sundmacher, K.: The impact of mass transport and methanol crossover on the direct methanol fuel cell. J. Power Sources 83, 204-216 (1999)

8. Xie, S., Tong, X.-L., Jin, G.-Q., Qin, Y., Guo, X.-Y.: CNT-Ni/ $\mathrm{SiC}$ hierarchical nanostructures: preparation and their application in electrocatalytic oxidation of methanol. J. Mater. Chem. A 1, 2104-2109 (2013)

9. Cao, H., Fan, Z., Hou, G., Tang, Y., Zheng, G.: Ball-flowershaped $\mathrm{Ni}$ nanoparticles on $\mathrm{Cu}$ modified $\mathrm{TiO} 2$ nanotube arrays for electrocatalytic oxidation of methanol. Electrochim. Acta 125, 275-281 (2014)

10. Zhang, H., Gu, C.-D., Huang, M.-L., Wang, X.-L., Tu, J.-P.: Anchoring three-dimensional network structured $\mathrm{Ni}-\mathrm{P}$ nanowires on reduced graphene oxide and their enhanced electrocatalytic activity towards methanol oxidation. Electrochem. Commun. 35, 108-111 (2013) 
11. El-Shafei, A.A.: Electrocatalytic oxidation of methanol at a nickel hydroxide/glassy carbon modified electrode in alkaline medium. J. Electroanal. Chem. 471, 89-95 (1999)

12. Tehrani, R.M.A., Ab Ghani, S.: The Nanocrystalline Nickel with Catalytic Properties on Methanol Oxidation in Alkaline Medium. Fuel Cells 9, 579-587 (2009)

13. Ren, L., Hui, K.S., Hui, K.N.: Self-assembled free-standing threedimensional nickel nanoparticle/graphene aerogel for direct ethanol fuel cells. J. Mater. Chem. A 1, 5689-5694 (2013)

14. Raoof, J. B., Ojani, R., Hosseini, S. R.: An electrochemical investigation of methanol oxidation on nickel hydroxide nanoparticles. S. Afr. J. Chem. 66:00-00 (2013)

15. Ureta-Zañartu, M.S., González, T., Fernández, F., Báez, D., Berríos, C., Gutiérrez, C.: Electro-oxidation of benzyl and aliphatic alcohols on polynitspc-and $\mathrm{Ni}(\mathrm{OH})$ 2-modified glassycarbon and gold electrodes. Int. J. Electrochem. Sci. 7 (2012)

16. Li, Q., Zeng, G.-Z., Zhao, W.-F., Chen, G.-H.: Preparation and characterization of nickel-coated graphite nanosheets. Synth. Met. 160, 200-202 (2010)

17. Jenkins, R., Snyder, R.L.: Introduction to X-Ray Powder Diffractometry. John Wiley \& Sons; 1996

18. Bard, A. J., Faulkner, L. R.: Electrochemical methods: fundamentals and applications. Wiley, (2000)

19. Golikand, A.N., Asgari, M., Maragheh, M.G., Shahrokhian, S.: Methanol electrooxidation on a nickel electrode modified by nickel-dimethylglyoxime complex formed by electrochemical synthesis. J. Electroanal. Chem. 588, 155-160 (2006)

20. Fleischmann, M., Korinek, K., Pletcher, D.: The oxidation of organic compounds at a nickel anode in alkaline solution. J. Electroanal. Chem. Interfacial Electrochem. 31, 39-49 (1971)

21. Taraszewska, J., Rosłonek, G.: Electrocatalytic oxidation of methanol on a glassy carbon electrode modified by nickel hydroxide formed by ex situ chemical precipitation. J. Electroanal. Chem. 364, 209-213 (1994)

22. Abdel Rahim, M.A., Abdel Hameed, R.M., Khalil, M.W.: Nickel as a catalyst for the electro-oxidation of methanol in alkaline medium. J. Power Sources 134, 160-169 (2004)

23. Danaee, I., Jafarian, M., Forouzandeh, F., Gobal, F., Mahjani, M.G.: Electrochemical impedance studies of methanol oxidation on $\mathrm{GC} / \mathrm{Ni}$ and $\mathrm{GC} / \mathrm{NiCu}$ electrode. Int. J. Hydrogen Energy 34, 859-869 (2009)

24. Singh, R.N., Singh, A., Anindita Mishra, D.: Influence of the nature of conductive support on the electrocatalytic activity of electrodeposited $\mathrm{Ni}$ films towards methanol oxidation in $1 \mathrm{M}$ KOH. Int. J. Hydrogen Energy 33, 6878-6885 (2008)

25. Xu, C., Hu, Y., Rong, J., Jiang, S.P., Liu, Y.: Ni hollow spheres as catalysts for methanol and ethanol electrooxidation. Electrochem. Commun. 9, 2009-2012 (2007) 